\title{
Call Timing of Callable Non-Convertible Bonds: A Survival Analysis
}

\author{
Jung Bum Wee ${ }^{1}$, Keunkwan Ryu ${ }^{2, *}$ and Ki Beom Binh ${ }^{3}$ \\ ${ }^{1}$ Department of Management, Kyung Hee University, Seoul, Korea \\ ${ }^{2}$ Department of Economics, Seoul National University, Seoul, 1 Gwanak-ro, Gwanak-gu, Seoul 08826, Korea \\ ${ }^{3}$ Department of Economics, Myongji University, Seoul, Korea
}

\begin{abstract}
We empirically analyze the factors affecting corporate decisions to call non-convertible bonds using survival analysis. The results show that firms tend to defer calling non-convertible bonds in order to mitigate agency costs of debt (including under-investment and risk-shift); that calling is significantly more intense if positive information is revealed; that non-refundability clauses are binding on call decisions; that firms are more likely to redeem bonds to refund if market interest rates fall dramatically; and that this interest effect is stronger as the transaction costs of refunding decrease. Also, this paper shows that call intensity monotonically decreases after call protection periods expire.
\end{abstract}

Keywords: Call hazard rate, callable non-convertible bond, embedded call option, percentage life, duration.

\section{INTRODUCTION}

While many current works address the decision whether to include a call feature in bond covenants, this paper focuses on why calls are made on nonconvertible bonds. In regards to calling, Vu (1986) analyzes call premium, the call price over the market price of bonds, and finds that firms are motivated to exercise call options to remove restrictive bond covenants. King and Mauer (2000) examine call delays of non-convertible bonds beyond the time the price of a bond first hits the call price. Their previous findings suggest that call delays are shorter when the firm size (proxy of sophistication) is larger; the firm is less liquidity constrained; the interest savings resulting from calling and refinancing is larger; the volatility of interest rates (proxy of the continuation value of call option) is lower; the slope of the term structure (proxy for future interest rate) is steeper.

For the purpose of our study, the method of analyzing why managers make the decision to call nonconvertible bonds is the survival analysis technique. We estimate the entire time path of the hazard rate, the conditional likelihood of calling, over the lifetime of a bond. We analyze the effect of the refunding opportunity, of the agency problems of debt, and of the cost of financial distress on call timing.

Firms utilize available information up until the time the decision to call is made. The decision to call on a

*Address correspondence to this author at the Department of Economics, Seoul National University, 1 Gwanak-ro, Gwanak-gu, Seoul 08826, Korea; Tel: +82-2-880-6397; Fax: +82-2-886-4231; E-mail: ryu@snu.ac.kr JEL: C41, G11, G30, G32. non-convertible bond is not necessarily fixed at issuance; instead the decision to call is the result of a sequence of consecutive decisions. Our findings suggest that:

Firms tend to defer calling non-convertible bonds to mitigate the agency cost of debt such as underinvestment and risk-shift.

- Calling is significantly more intense if positive information is revealed.

- Non-refundability clauses are binding in call decisions.

- $\quad$ Firms are more likely to redeem bonds to refund if the market interest rate falls dramatically.

- The strength of this interest effect gets stronger as the transaction cost of refunding decreases.

- After the end of call protection periods, call intensity monotonically decreases.

- $\quad$ Callable bonds with relatively longer spans tend to live shorter percentage lives.

Our paper is organized as follows: Section 2 draws testable hypotheses regarding the effect on calling nonconvertible bonds of the various factors identified in the existing literature. Section 3 discusses measurement issues and describes the empirical model. Section 4 explains the data sources and presents selective summary statistics. Section 5 shows the estimation results. Section 6 concludes the paper. Other details regarding measurement issues, summary statistics, and empirical results can be found in the appendix. 


\section{HYPOTHESIS REGARDING CALL DECISION: A THEORETICAL OVERVIEW}

After considering the factors discussed by $\mathrm{Vu}$ (1986), King and Mauer (2000), and Sarkar (2001), the result is a set of underlying factors that is expected to influence corporate decisions to call non-convertible bonds. For example, Sarkar postulates that those factors affecting the decision to include a call option affect the call timing decision as well. We also analyze the factors affecting the decision whether to include a call option. Other underlying factors include interest costs, agency costs of debt (such as under-investment, risk-shift and informational asymmetry), costs of financial distress, call protection clauses, and costs of re-capitalization.

\subsection{Refunding at Lower Interest Rates}

When existing debts can be refunded at lower costs, firms decide whether to act when presented with an incentive to call. Pye (1966) views a call provision as an option to redeem a bond and refund it at a lower cost when the market interest rate falls. But the potential benefits of refunding depend on both interest savings and transaction costs. Firms are more likely to call in debt the greater the benefits of refunding and the lower the transaction costs.

We proxy interest savings with the spread of a bond's coupon rate over the market interest rate (DINT). The market interest rate is measured by the one-year Treasury bill rate in the secondary market. There is a trade-off in measuring the market interest rate using long-term rates and short-term rates. Longterm rates are favored because any refinancing would be long-term in nature. Most callable bonds mature after a year.

Firms may save call options, anticipating a drop in the long-term interest rate in the future. Short-term rates signal future trends in long-term interest rates. Just because a firm has not called a bond yet, does not mean the firm is unwilling to refinance until maturity. As a compromise, we choose the one-year rate as the representative rate.

In regards to refunding transaction costs, we postulate that there is an economy of scale in the refunding transaction. Further, we claim that unit refunding costs decrease with the size of bond issue. We proxy the size of issue with the natural logarithm of the authorized amount $(\operatorname{In}($ Amount $))$.

\subsection{The Agency Problem of Debt}

\subsubsection{Under-Investment and Asset Substitution}

Smith and Warner (1979) argue firms issue bonds with a call feature to mitigate the agency problem of debt: including under-investment and asset substitution. The presence of an unexercised call option provides managers or shareholders with an incentive to commit to firm-value maximization. Their endeavor to enhance firm value will be rewarded if the firm calls the bond and refunds. Thus, firms in debt tend to defer calling and leave call options unexercised.

Agency cost of debt becomes more severe as a firm becomes more prone to default. We proxy default possibility with indebtedness (DEBT) and measure by the ratio of total liability to total asset.

\subsubsection{Informational Asymmetry}

Good firms suffer from adverse selection if there is information asymmetry between the managers and the outside investors. Stein (1992) suggests that good firms stipulate call provisions in bond issues. These firms can then refund at a lower cost in case private information is revealed after issuance. Firms are more likely to exercise a call option if positive information has been revealed.

We proxy the content of the released information with the reported profit, and measure by the ratio of net income to total assets (PRO).

\subsection{Issues Related with Call Protection Clauses}

\subsubsection{Non-Callability and Non-Refundability}

Callable bonds usually have a covenant prohibiting an issuer from calling the bond under certain circumstances. The contents of call protection clauses differ across issues. We label a provision as noncallable (or "absolute call protection") if the covenant strictly prohibits calling for a pre-specified period, and non-refundable (or "conditional call protection") if the covenant bans the issuer from calling the bond to refund at a lower interest rate.

Conditional call protections protect bondholders from forced reinvestment as a result of a call that would most likely have a return that is lower than the retiring bond's interest rate. On the other hand, its existence suggests that firms include a call option for purposes other than refunding at a lower interest rate.

Thatcher (1985) postulates that to mitigate agency costs of debt, firms reserve the right to call a bond even 
during the call protection period, if it is not for refunding at a lower coupon rate. However, Allen et al. (1987) find that the length of an additional conditional call protection period does not influence bond yields, while the absolute one leads to lower yields on primary bond issues. They interpret this result as implying that nonrefundability is not truly binding because a firm could easily circumvent it by refunding long after the retirement of bond. Further, Crabbe and Helwege (1994) attempt to distinguish different sources of agency problems, and find that agency theory is unlikely to be the most important explanation of the call protection clause.

We investigated whether firms showed different call hazard rates when they were free to call bonds compared with when they were constrained by conditional call protection. If firms are more likely to call bonds when they are free, it implies that nonrefundability is binding and that refunding at a lower cost is not the only reason to exercise call options.

Included is a dummy variable $D_{\text {FREE }}$ that measures the presence or absence of freedom for calling. It takes the value 0 if a conditional protection clause exists and is currently binding, and 1 otherwise. For the callable bonds with conditional call protection clauses, this dummy variable becomes time varying. It takes a value of zero during the conditional call protection period and one thereafter. Of course, for callable bonds without a conditional call protection clause, this dummy variable is time constant and takes a value of one throughout.

\subsubsection{Agency Problem of Re-Capitalization}

Firms must deal with an additional agency problem. Fischer et al. (1989) postulate that the shareholders' preferred call time is earlier than firms' preferred call time. This generates a potential "agency cost of recapitalization." A firm eventually bears the burden because bondholders demand a higher yield. Thus, firms attempt to commit to calling no earlier than the firm-value maximizing time by setting a call protection period that immediately follows the issuance.

We use the so-called baseline hazard function to capture this effect: which shows the changing pattern of call hazard rates as time passes. This point is further explained in the next section.

\subsection{The Cost of Financial Distress}

If a firm is in financial distress, it is likely to go through financial restructuring. Financial distress incurs direct costs, including legal expenses, as well as indirect costs, such as excessive interest cost. A bond may be called to reduce the possibility of financial distress by securing a chance to restructure financially. For instance, Barnea et al. (1980) point out that firms can eliminate a default risk and thereby the incentive problem of debt if they can issue a callable bond with state-contingent call prices.

However, it is also possible that default risks may keep firms from retiring existing debts. Firms may have difficulty in raising new funds if they are liquidityconstrained. Thus, these two opposing forces render the effect of the chance and the cost of financial distress on calling unpredictable.

Both the chance and the cost of financial distress are proxied with the ratio of fixed assets to total assets (FASS). Fixed assets, including tangibles and nontangibles, are more likely to be firm specific and to have low sale prices during restructuring, compared to current assets that are mostly cash, securities, and inventories. Further, firms are more likely to be liquidityconstrained as the proportion of fixed assets increases.

\section{MEASUREMENT ISSUES AND THE EMPIRICAL MODEL}

Within this paper, we estimate the hazard rate of call. Hazard rate of call shows the call intensity at each moment in time as a function of the available information at that time. Hazard rate of call measures the duration. Duration is the interval from the time when calling becomes possible to the time when calling is in fact made. Note that the term "duration" here is distinct from the usual meaning of duration in finance literaturethat is, weighted average maturity of a bond.

On the other hand, we can regard the call and conversion for callable and convertible bonds as competing risks. These can be formulated to have each hazard. As mentioned, we focus callable nonconvertibles not callable convertibles. This is because they are so different. So we analyze the callable convertibles in another paper.

\subsection{The Measurement of Duration}

Measuring the duration of a callable bond is not straightforward since different structures appear across different callable bonds. For example, time horizons are different for different bonds. Protection periods exist for some but not for others. Absolute call protection periods that prohibit calling regardless of 


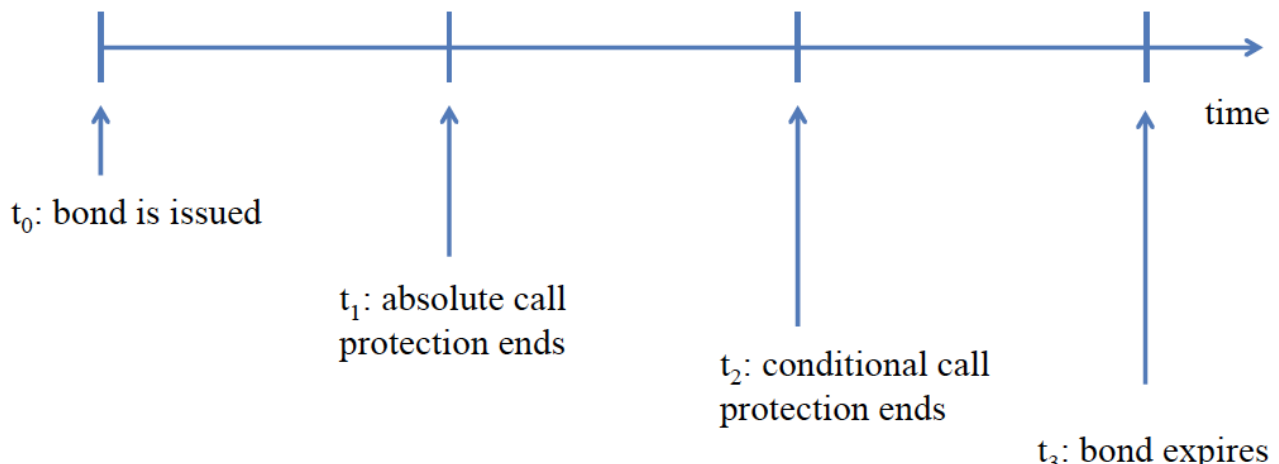

Figure 1: Hypothetical life path of callable bonds.

circumstances, range from several months to several years, if they exist. Conditional call protection periods that prohibit calling unless certain specified conditions are satisfied, may not exist. When they exist, they range from several months to several years. Also, time intervals from the end of the absolute call protection period to call expiration are all different.

Figure 1 illustrates a hypothetical life path of a callable non-convertible bond. There are four possible time points, $t_{0}, t_{1}, t_{2}$, and $t_{3}$, in increasing order. For example, a firm issues a callable bond at time $t_{0}$. The bond matures at time $t_{3}$. The bond is absolutely not callable until $t_{1}$. The bond is conditionally not callable further until $t_{2}$ elapses unless a set of certain conditions is met. After $t_{2}$, the bond is callable without restriction.

We call the time interval from $t_{0}$ to $t_{1}$ an absolute call protection period, and the time interval from $t_{1}$ to $t_{2}$ a conditional call protection period. When there is no absolute call protection period, we set $t_{0}=t_{1}$. When there is no conditional call protection period, we set $t_{1}=t_{2}$. The conditional call protection clause typically stipulates that the bond cannot be called before $t_{2}$, when refunding is made at a lower interest rate than the bond's interest rate.

Duration is measured as the time interval from the end of the absolute call protection period to the actual call time. Duration measures how long the bond issuer waits until s/he exercises the call option after calling becomes possible. However, the absolute length of calendar time is not a good measure.

To illustrate, consider two callable bonds differing in callable life spans, i.e., suppose one bond has a 10year life span and the other bond has a 2-year life span. If both bonds were called after one year of call eligibility, the call would have been exercised much earlier, in relative terms, for the first bond than for the second. The first bond survived only $10 \%$ of its callable life, whereas the second bond survived $50 \%$ of its callable life. Because absolute length of calendar time is not a good measure, we must define "duration" in a more meaningful way.

Therefore, we adopt the percentage life as a measure of duration herein. Percentage life is the ratio $\left(t_{c}-t_{1}\right) /\left(t_{3}-t_{1}\right)$, where $t_{c}$ is the observed call time if a call is made and is equal to $t_{3}$ if no call is made until maturity. The application of percentage life yields a more meaningful comparison of duration across bonds of different maturities.

Call observations are classified into three categories. First, there are bonds that are called during the sample period. These are considered complete observations because a call is observed and they have a value of duration of less than one. Second, there are bonds that are not called nor mature by the end of the sample period. These bonds are incomplete and have a value of duration of less than one. Finally, there are bonds that are not called until maturity. These observations are maturity censored. For such observations, the duration has a value of one.

Let us explain the censoring. The censored data has literally limited information. So we never know events out of our sample. That is, we do not see what happened after the above second type observed duration. Even if we get the information, we should include them into our sample in this paper. So such data are called censored. And the censored data in our study is right-censored.

\subsection{The Empirical Model}

The empirical model is a hazard rate model specified as follows: 
$h\left(t \mid x_{t}\right)=h_{0}(t) \exp \left(x_{t}{ }^{\prime} \beta\right)$

Here $h\left(t \mid x_{t}\right)$ is the call hazard rate at time $t$ given $x_{t}, h_{0}(t)$ is the so-called baseline hazard function, $x_{t}$ is a collection of the explanatory variables available at time $t$, and $\beta$ is a vector of unknown parameters. To ensure it is always positive, we represent $h_{0}(t)$ as $h_{0}(t)=\exp \left(g_{0}(t)\right)$ so that the resulting hazard function becomes:

$h\left(t \mid x_{t}\right)=\exp \left(g_{0}(t)+x_{t}{ }^{\prime} \beta\right)$.

To test the theoretical implications, we let $x_{t}$ include those covariates discussed in the previous section. Many covariates are time varying in nature. Since firms' financial situations and other environments continuously change, using these time varying covariates to explain managers' decisions to call at any moment in time is better.

To complete the model, we still need to specify $g_{0}(t)$. We use a step function for $g_{0}(t)$ by introducing a set of sub-interval dummy variables to partition the unit interval. To design the partition to be used, we consider a trade-off between flexibility and reliability. If a finer partition is used, the resulting function becomes more flexible but less reliable, and vice versa. The chosen sub-intervals in the partition are progressively wider over time to avoid the problem of thin data at later time intervals. We end up partitioning the unit interval into five sub-intervals, $\{[0,0.1],(0.1,0.2],(0.2,0.3],(0.3,0.5]$, $(0.5,1]\}$ by introducing four collapsed time dummy variables indicating the first four sub-intervals. The coefficient of the first dummy variable shows whether the call hazard rate is higher (+) or lower (-) in the first sub-interval (birth to $10 \%$ of age) relative to the second half of the callable life span, and similarly for other dummies.

To sum, the set of variables used in our model is as follows:

- $\quad$ Time varying covariates: FASS is the ratio, (fixed asset)/(total asset). DEBT is the ratio, (total liability)/(total asset). PRO is the ratio, (net income)/(total asset). $D_{\text {FREE }}$ is the dummy variable measuring freedom from conditional call protection periods. It takes the value 0 if a conditional protection clause exists and is currently binding, and 1 otherwise. DINT is the difference, the bond's interest rate (\%) minus the one-year Treasury bill rate (\%).

- $\quad$ Time constant covariates: $\operatorname{In}$ (Amount) is the natural logarithm of the authorized amount of bond issue measured in million US dollars. Callable life span is the length of time from the end of the absolute call protection period to maturity measured in 10 years.

- $\quad$ Baseline hazard function: $\mathrm{D}[0,0.1], \mathrm{D}(0.1,0.2]$, $\mathrm{D}(0.2,0.3]$ and $\mathrm{D}(0.3,0.5]$ are sub-interval dummies that take a value of one on the intervals $[0,0.1],(0.1,0.2],(0.2,0.3]$ and $(0.3,0.5]$ respectively. These four dummy variables together with an overall constant term model the baseline hazard function as a step function with five steps.

\subsection{The Baseline Hazard}

As discussed in the previous section, Fischer et al. (1989) provide an implication for the shape of the baseline hazard function. Managers should call bonds as soon as when doing so benefits shareholders. This maxim implies that call intensity should be highest at this shareholder-wealth maximizing time of calling, but the shareholder-wealth maximizing time of calling is earlier than the firm-value maximizing time. To resolve this gap, firms could match the expiration of a call protection period and the firm-value maximizing time. Then, the firm would have an incentive to call bonds immediately after the expiration of a call protection period. This is illustrated in Figure 2.

The time origin for duration coincides with the end of the call protection period for a bond without a conditional call protection clause because we measure the duration from the end of the absolute call protection period. For these bonds, their argument implies that the baseline hazard function is monotonically decreasing.

The time origin does not necessarily coincide with the end of the call protection period for bonds with a conditional call protection clause. For these bonds, the effective ending of call protection varies widely depending on the structure of the conditional call clauses and also on whether the condition is met. Figure $\mathbf{A} 1$ in the appendix depicts how widely lengths of the conditional call protection period vary.

In our sample, a majority of callable non-convertible bonds do not have conditional call protection clauses. We expect this monotonically decreasing baseline hazard pattern to be visible in calling non-convertible bonds, in particular the ones without a conditional call protection clause. 
intensity to call

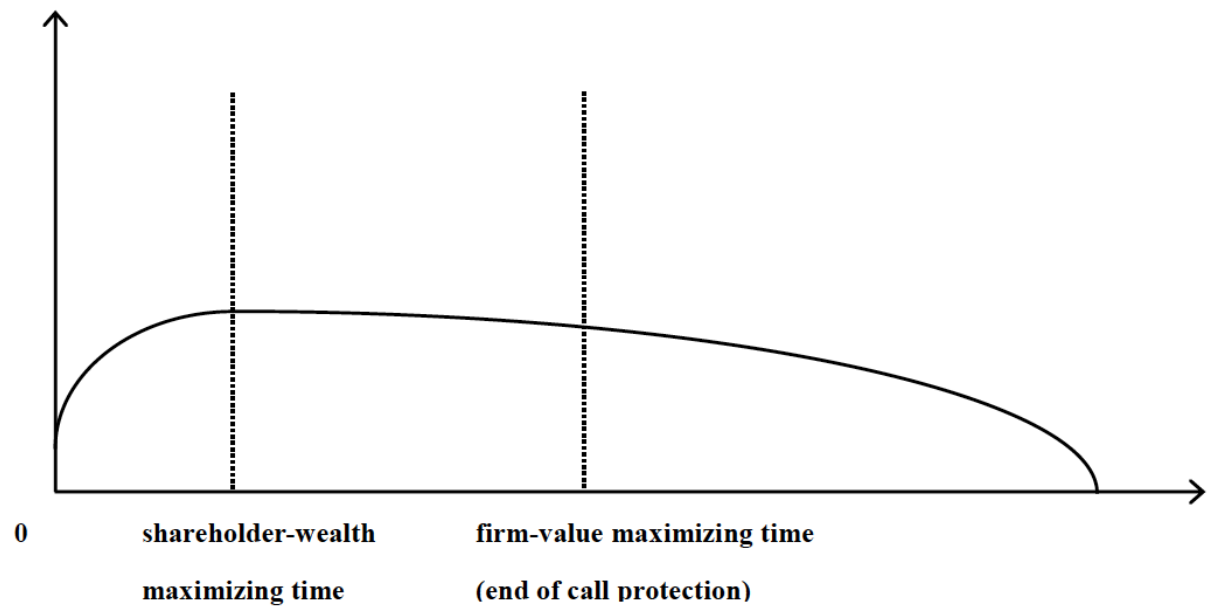

Figure 2: Call protection and call intensity.

\subsection{The Construction of the Likelihood Function}

Let $T$ be the random variable denoting the duration measured in percentage life. To construct the likelihood function, we need to compute the probabilities of the following two forms,

$f(T=t)$ and $P(T>t), 0 \leq t \leq 1$

when the first denotes the density of the event $T=t$ (complete observation) and the second denotes the probability of the event $T>t$ (right-censored, whether incomplete or maturity censored).

Suppose $T=0.35$ and $T>0.35$. First, $T=0.35$ means that a callable bond survives $35 \%$ of its callable life and then is called immediately at $35 \%$ location of its callable life span. By using a relationship between the hazard rate function and the density function, we end up with,

$$
\begin{aligned}
& f(T=0.35)=\exp \left(g_{0}(0.35)+x_{0.35}{ }^{\prime} \beta\right) \\
& \exp \left[-\int_{0}^{0.35} \exp \left(g_{0}(u)+x_{u}{ }^{\prime} \beta\right) d u\right]
\end{aligned}
$$

Second, $T>0.35$ means that a callable bond is only known to have survived $35 \%$ of its callable life. Similarly, we find

$$
P(T>0.35)=\exp \left[-\int_{0}^{0.35} \exp \left(g_{0}(u)+x_{u}{ }^{\prime} \beta\right) d u\right]
$$

We need to address two issues in order to compute the likelihood values. First, time-varying covariates are recorded according to the calendar time (either monthly or yearly), not normalized time. We need to rearrange them according to normalized time. This point leads us to a second issue. Since time horizons vary across different callable bonds, arrangement must be done on an individual basis (details are in the appendix).

\section{DATA}

In this section, we explain the data sources and present some basic statistics before carrying out the survival analyses in the next section.

\subsection{Data Sources}

The sample of callable non-convertible bonds is taken from those listed in Moody's Industrial Manuals. The sample bonds were issued between September 1, 1980 and December 31, 1991. Moody's Manuals provide important features of bonds: issuance date, call protection period, maturity, face value, coupon rate, and call date. Data to construct explanatory variables were collected from Compustat files, the Citibank database, Center for Research in Security Prices (CRSP) files, and the International Financial Statistics. Compustat files provided firm characteristics such as net income, liabilities, net fixed assets, and total assets. The market interest rates were taken from the Citibank database. CRSP files provided rates of return data. As a relevant price index, we used the industrial price index available from International Financial Statistics.

The sample excludes bonds that are retired or suspected to have retired before or after a major merger or acquisition. Specifically, the sample excludes bonds called by either an acquiring or an acquired firm 12 months before and 6 months after a major merger or acquisition. The sample also excludes bonds wherein the issuing firm goes bankrupt after issuance. 
This is to preclude observations that are likely to show deviant call patterns. Also, we exclude observations that lack some relevant information such as financial ratios or the coupon rate. In the end, we have 586 usable observations for callable non-convertible bonds.

\subsection{Descriptive Statistics}

Table 1 shows selected sample data used in this paper. Table 2 cross-tabulates the sample bonds by the presence or absence of an absolute call protection clause, and the presence or absence of a conditional call protection clause. Most callable bonds have either an absolute call protection clause or a conditional call protection clause, but seldom both. We infer that the two types of call protection clause function as substitutes rather than as complements in providing protection to investors.

Figures 3 and $\mathbf{4}$ shows the distribution of the length of the absolute (conditional) call protection period for the sub-sample with absolute (conditional) call protection. The mean length of the absolute

Table 1: Selected Sample Data: Callable Non-Convertible Bonds

\begin{tabular}{|c|c|c|c|c|c|c|}
\hline Company name & $\begin{array}{l}\text { Issuance } \\
\text { date }\end{array}$ & $\begin{array}{l}\text { Acquisition } \\
\text { date }\end{array}$ & $\begin{array}{c}\text { End of } \\
\text { absolute call } \\
\text { protection }\end{array}$ & $\begin{array}{c}\text { End of } \\
\text { conditional } \\
\text { call protection }\end{array}$ & Call date & $\begin{array}{l}\text { Expiration } \\
\text { date }\end{array}$ \\
\hline Abbott Industries & 19830201 & . & 19900201 & . & 19900201 & 19930201 \\
\hline Allied Siganl Inc (Allied Corp) & 19831001 & 19850919 & . & 19941101 & 19870227 & 20091101 \\
\hline American Medical Holdings Inc & 19840115 & . & . & 19940115 & 19870819 & 20140115 \\
\hline American Medical Holdings Inc & 19850601 & . & 19920601 & . & 19920610 & 19950601 \\
\hline American Medical Holdings Inc & 19850601 & . & . & 19950601 & 19930701 & 20150601 \\
\hline American Medical Holdings Inc & 19860115 & . & 19900115 & . & 19910115 & 19910115 \\
\hline Atlantic Richfield Co & 19820915 & . & . & 19920915 & 19870430 & 20120915 \\
\hline Atlantic Richfield Co & 19830415 & . & . & 19930415 & 19900301 & 20130415 \\
\hline Atlantic Richfield Co & 19850601 & . & . & 19950601 & 19900301 & 20150601 \\
\hline Atlantic Richfield Co & 19851015 & . & 19921015 & . & 19930101 & 19951015 \\
\hline Atlantic Richfield Co & 19860101 & . & 19930101 & . & 19930101 & 19960101 \\
\hline Baxter Int'I Inc & 19870615 & . & 19880615 & . & 19930701 & 20180615 \\
\hline Baxter Int'I Inc (American Hosp. Supply) & 19820815 & 19851125 & 19890901 & . & 19890901 & 19920901 \\
\hline Cabot Corp & 19820801 & . & . & . & 19860930 & 19920801 \\
\hline Cabot Corp & 19841101 & . & . & 19911101 & 19870427 & 19941101 \\
\hline Comdisco Inc & 19860515 & . & 19920515 & . & 19920629 & 19940515 \\
\hline Data General Corp & 19850515 & . & . & 19950515 & 19870518 & 20150515 \\
\hline Digital Equipment Corp & 19840401 & . & 19910415 & . & 19910415 & 19940415 \\
\hline Digital Equipment Corp & 19840415 & . & . & 19940415 & 19860619 & 20140415 \\
\hline
\end{tabular}

Note. In the case of acquisition, the firm outside the parentheses acquires the firm within parentheses. If another firm acquires an issuing firm during the life of the callable bond, we use the acquisition date instead of the original issuance date as the birth date of the bond. 
Table 2: Joint Distribution of Existence of Absolute and Conditional Call Protection Clauses

\begin{tabular}{|c|c|c|c|}
\hline \multirow{2}{*}{\multicolumn{2}{|c|}{ Non-convertible bonds }} & \multicolumn{2}{|c|}{ Conditional call protection period } \\
\hline & & Exist & Not exist \\
\hline \multirow{2}{*}{ Absolute call protection period } & Exist & $4 \%$ & $48 \%$ \\
\hline & Not exist & $36 \%$ & $12 \%$ \\
\hline
\end{tabular}

(conditional) call protection period is 5.14 (8.79) years for the sub-sample.

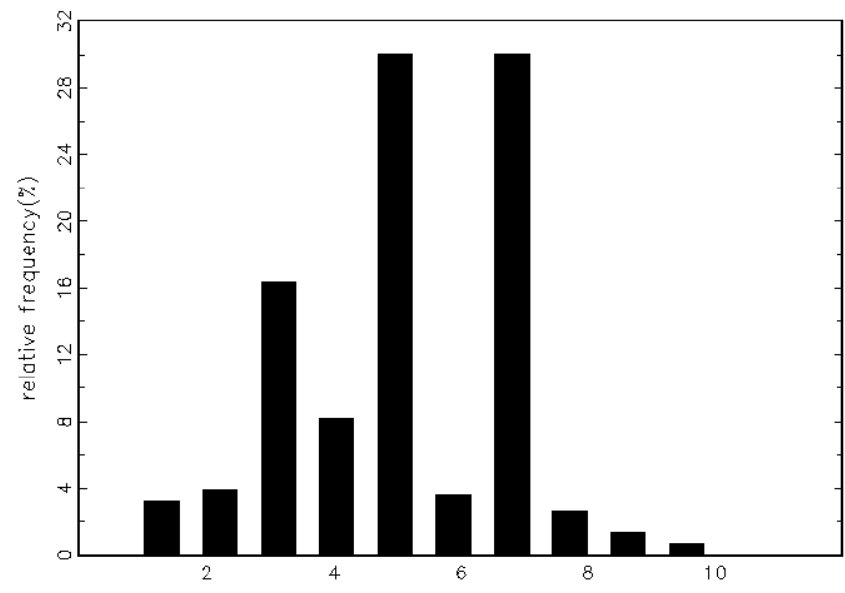

length af absolute call protection period(year)

Figure 3: Histogram showing length of absolute call protection period: callable non-convertible bonds with an absolute call protection period.



Figure 4: Histogram showing length of conditional call protection period: callable non-convertible bonds with a conditional call protection period.

Table 3 shows a classification of the sample data by censoring status. Out of 586 cases, 367 bonds were called before maturity, and only 46 bonds were not called until maturity. The rest of the bonds form a group of incomplete observations, as they are only known to have survived a certain percentage life.
Table 3: Classification of Sample Data by Censoring Status

\begin{tabular}{|c|c|c|}
\hline & Total Number & Proportion (\%) \\
\hline \hline Complete & 367 & 62.6 \\
\hline Incomplete & 173 & 29.5 \\
\hline Maturity censored & 46 & 7.8 \\
\hline Total & 586 & 100.0 \\
\hline
\end{tabular}

The below Table 4 shows mean and standard deviations of the covariates used in our empirical model.

Table 4: Mean and Standard Deviation of Covariates Used for Estimation

\begin{tabular}{|c|c|c|}
\hline & Mean & SD \\
\hline \hline FASS & 0.41 & 0.21 \\
\hline DEBT & 0.36 & 0.20 \\
\hline PRO & 0.03 & 0.08 \\
\hline D FREE & 0.41 & 0.49 \\
\hline DINT (\%) & 4.33 & 2.80 \\
\hline In(Amount) & 4.75 & 0.84 \\
\hline Callable life span (year) & 13.70 & 11.50 \\
\hline
\end{tabular}

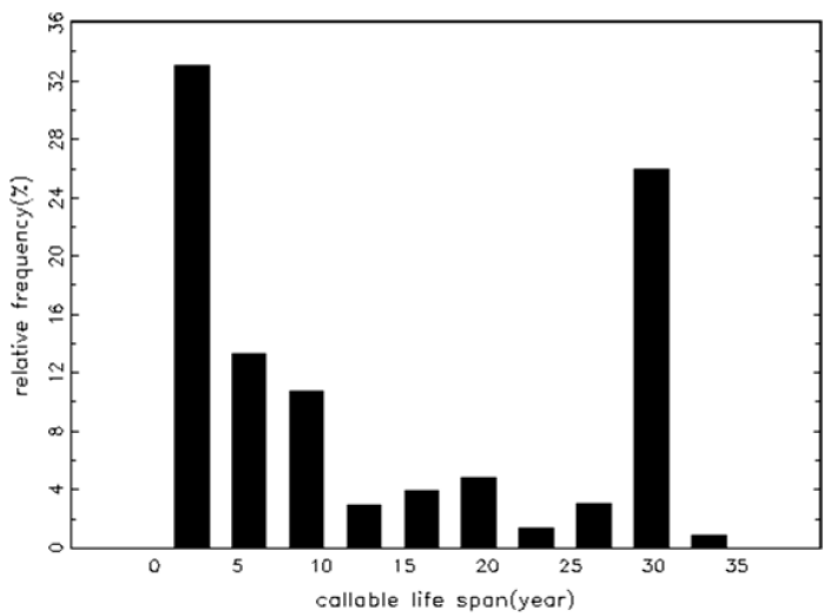

Figure 5: Histogram showing callable life span.

Figure 5 shows the distribution of the callable life span $\left(t_{3}-t_{1}\right)$. Here we are using an absolute time 
scale, not a relative one. It shows that the length of callable life span varies a lot across different callable bonds. We controlled the callable life span when estimating the duration model.

\section{RESULTS}

Table $\mathbf{5}$ shows the estimation results. Table A1 in the appendix present the estimation results for the subsamples, classified according to the presence or absence of a conditional call protection period. Findings are basically the same as those reported in Table 5, other than that the statistical significance in general drops due to a sample split.

Following is a summary of our findings.

First, calling a non-convertible bond does not appear to be influenced by the chance or the cost of financial distress [FASS]. This might be because the two effects offset each other. To reduce the possibility of financial distress, a firm may either call existing debt to re-capitalize or simply postpone calling not to face liquidity-constraints.

Second, calling tends to be deferred if the degree of indebtedness is large. This supports the idea that the existence of an unexercised call option helps to mitigate the under-investment or risk-shift problem.
This result is also consistent with the financial distress argument, since the extent of liquidity-constraint may be positively correlated with indebtedness.

Third, firms tend to speed up calling if positive information is revealed. This effect is found to be significant regardless of whether the sample is split according to the presence or absence of a conditional call protection clause.

Fourth, firms are less likely to call a bond if it is restrained by a non-refundability clause. This suggests that non-refundability is indeed binding, and that agency arguments may explain the call protection clause. It is more consistent with Thatcher (1985) than with Allen et al. (1987) or Crabbe and Helwege (1994).

Fifth, to identify the call timing effect of the refunding opportunity and to see how it interacts with transaction costs, we estimated the effects of the interest rate spread on the call hazard rate as a function of transaction costs. Specifically, $\frac{\partial \ln h\left(t \mid x_{t}\right)}{\partial D N I T}=0.12+0.06 *$ $\ln$ Amount. The effect on calling of the interest rate spread get stronger as the unit refunding transaction cost drops.

Sixth, the baseline hazard function shows a monotonically decreasing pattern. Tables $\mathbf{A} 1$ in the

Table 5: Call Hazard Function Estimation

\begin{tabular}{|c|c|c|c|c|c|}
\hline Variable & Estimate & Expected Sign & Standard Error & t-value & p-value \\
\hline Constant & $-2.62^{\star * \star}$ & & 0.38 & -6.97 & 0.00 \\
\hline $\mathrm{D}[0,0.1]$ & $1.57^{\star \star \star \star}$ & + & 0.22 & 7.15 & 0.00 \\
\hline $\mathrm{D}(0.1,0.2)$ & $0.77^{\star \star \star}$ & + & 0.23 & 3.36 & 0.00 \\
\hline $\mathrm{D}(0.2,0.3)$ & $0.83^{\star \star \star}$ & + & 0.24 & 3.46 & 0.00 \\
\hline $\mathrm{D}(0.3,0.5)$ & $0.78^{\star \star \star *}$ & + & 0.23 & 3.45 & 0.00 \\
\hline FASS & 0.39 & 0 & 0.34 & 1.15 & 0.25 \\
\hline DEBT & $-2.23^{* * \star}$ & - & 0.40 & -5.59 & 0.00 \\
\hline PRO & $4.98^{* * *}$ & + & 1.21 & 4.10 & 0.00 \\
\hline$D_{\text {FREE }}$ & $0.66^{* * \star}$ & + & 0.18 & 3.61 & 0.00 \\
\hline DINT & $0.12^{*}$ & + & 0.06 & 1.95 & 0.05 \\
\hline DINTxIn(Amount) & $0.06^{* * *}$ & + & 0.01 & 5.35 & 0.00 \\
\hline Callable life span & $0.21^{\star \star \star}$ & $?$ & 0.09 & 2.44 & 0.01 \\
\hline
\end{tabular}

$\mathrm{D}[\mathbf{0}, \mathbf{0 . 1}], \mathbf{D}(\mathbf{0 . 1}, \mathbf{0 . 2}], \mathbf{D}(\mathbf{0 . 2}, \mathbf{0 . 3}]$ and $\mathbf{D}(\mathbf{0 . 3}, \mathbf{0 . 5}]$ are time-dummy variables defined on the intervals $[0,0.1],(0.1,0.2],(0.2,0.3]$ and $(0.3,0.5]$ respectively.

FASS is the ratio, (fixed asset)/(total asset).

DEBT is the ratio, (total liability)/(total asset)

PRO is the ratio, (net income)/(total asset).

$D_{\text {FREE }}$ is the dummy variable measuring freedom from conditional call protection periods. It is time varying and takes the value 0 if the callable bond is prohibited from being called by a conditional protection clause, and 1 otherwise.

DINT is the difference, the bond's interest rate minus the one-year Treasury bill rate.

Ln(Amount) is the natural logarithm of the authorized amount of the bond issue measured in 1 million dollars.

Callable life span is the length of time from $t_{1}$ to $t_{3}$ measured in 10 years. 
appendix show that this monotonic pattern is in fact only significant for non-convertible bonds without a conditional call protection clause, which is consistent with our prior expectation.

Seventh, callable bonds of a longer life span tend to live a shorter percentage life. This implies that the call times (measured in actual calendar time) of nonconvertible bonds are less spread than the callable life span themselves.

Lastly, in other model specifications not reported here (but available by request), we have included return volatility as an additional determinant of the call hazard rate. We tried two different measures. One is the standard deviation of the stock rates of return using the most recent 12-month data. The other is the standard deviation of stock rates of return using the most recent 24-month data. These volatility measures are time-varying in that they measure the volatility using the most recent data at each point in time. Option theory predicts that the higher the rate of return volatility, the higher the value of the conversion option. Thus, return volatility gives firms an incentive to exercise the call option early to preempt the conversion option of the bondholders. In our estimation, none of the volatility measures turn out to be statistically significant.

\section{CONCLUDING REMARKS}

The empirical results are consistent with the theoretical predictions that firms tend to defer calling non-convertible bonds to mitigate the agency cost of debt including under-investment and risk-shift; that calling is significantly more intense if positive information is revealed, which supports that callable bonds mitigate the transfer of wealth due to information asymmetry; that non-refundability clauses are indeed binding in call decisions; that a firm is more likely to redeem bonds to refund if the market interest rate falls; and that the interest effect is stronger as the transaction cost of refunding decreases.

Additionally, this paper shows that after the end of call protection periods, the call intensity monotonically decreases for non-convertible bonds; and that callable bonds with relatively longer life spans tend to live shorter percentage lives.

\section{ACKNOWLEDGEMENT}

Financial support from the Institute for Research in Finance and Economics of Seoul National University is gratefully acknowledged.

\section{APPENDIX: MEASUREMENT ISSUES, DESCRIPTIVE STATISTICS, AND OTHER RESULTS}

\section{A.1. The Measurement of Time}

Examples elucidate the various time concepts, the time intervals, and normalized duration. Consider the nonconvertible bond in Table 1 that was issued by Abbott Industries on February 1, 1983. There is no absolute call protection period. The company called the bond on January 1, 1987, before it could mature on February 1, 2013. Using the notation defined in the text, we have $t_{0}=t_{1}=1983 / 02 / 01$ (February 1, 1983), $t_{2}=1993 / 02 / 01$, $t_{c}=1987 / 01 / 01$, and $t_{3}=2013 / 02 / 01$. The callable life span is computed as follows (using one year as the measurement unit): $t_{3}-t_{1}=(2013-1983)+(2-2) / 12+(1-1) / 365=30$. The duration is $t_{c}-t_{1}=(1987-1983)$ $+(1-2) / 12+(1-1) / 365=3.92$. Finally, the normalized duration is computed as $t=\left(t_{c}-t_{1}\right) /\left(t_{3}-t_{1}\right)=3.92 / 30=0.14$. The callable bond is called after surviving $14 \%$ of its callable life.

For some observations, various calendar times are available up to a specific date; for others, they are only available up to months or years. In the latter case, we need approximations. We adopt mid-point approximation within an interval. For example, when a date is known only up to a year, say 1993, then 1993/07/01 is assigned. When a date is known up to a month, say January 1991, 1991/01/15 is assigned.

\section{A.2. Normalization and Time Varying Explanatory Variables}

At each moment in time, the decision to exercise a call option or not is made based on available information. In our data set, some covariates are measured annually and others monthly. Suppose it is July 10, 1986. To the corporate manager, yearly data is available for the years up to and including 1985 (up to the previous year) and monthly data is available for the months up to and including June 1986 (up to the previous month). We assume that data for the current year is not available for the yearly data and similarly that data for the current month is not available for the monthly data. 
In our data set, variables such as FASS, DEBT and PRO are recorded annually, and DINT is recorded monthly. These variables form time varying explanatory variables in our estimation. For these time varying variables, we assume that the most recently available data affect the decision to call and thus appear in the call hazard rate function. For example, in specifying the hazard rate for July 10, 1986, year 1985 values are used for the yearlyrecorded explanatory variables, whereas June 1986 values are used for the monthly-recorded explanatory variables.

Understanding how time varying explanatory variables are rearranged according to the normalized time is very important when properly assigning a likelihood value to each individual observation. Note that our hazard rate model uses the normalized time scale, whereas the data are recorded according to calendar time. This discrepancy needs to be reconciled. Since our explanatory variables are recorded discretely, we assume each explanatory variable only varies across different observation intervals and stays the same within each observation interval.

For each callable bond, we observe a realized sample path of each explanatory variable from birth to death, where a death is defined as the earliest time point among call time, right-censoring time, and maturity time. At a point in time between birth and death, the relevant value of the time varying explanatory variable is the most recent one. For each time-varying explanatory variable, a collection of the relevant values over the course of a call life forms a sample path. Once a realization of an explanatory variable path is constructed, we map it on to the normalized time scale. The resulting sample path in the unit time interval will be a step function covering the time horizon from birth to the percentage death point. The number of steps will be larger for the monthly-recorded data and smaller for the yearly-recorded data.

Once the sample paths are constructed over the unit interval for each of the time varying explanatory variables, we can easily compute individual likelihood values. This is because the integration appearing in the likelihood function (see subsection 3.4 of the text) reduces to summation due to the step function nature of the time varying explanatory variables as well as of the baseline hazard function.

Note that we have already modeled the baseline hazard function as a step function with five steps partitioning the unit interval. The partition points can be represented as a set: $A=\{0,0.1,0.2,0.3,0.5,1\}$. Given a callable bond, the sample path of a time varying variable recorded monthly will be a step function over the unit interval. This step function partitions the unit interval. Refer to the resulting set of partition points as $B$, which is common to all monthly data and to the set of partition points for the data yearly recorded as $C$. $C$ will be a subset of $B$. Let $D$ be the union of the above three sets: $A, B$, and $C$.

Then, the hazard rate $h\left(t \mid x_{t}\right)=\exp \left(g_{0}(t)+x_{t}{ }^{\prime} \beta\right)$ itself will become a step function in the unit interval with steps shifting only at points in set $D$. Using this hazard rate path, we can easily assign individual likelihood values. Note that sets $B$ and $C$ (and thus $D$ ) will be different depending on individual call structures. Therefore, we have to assign individual likelihood values on an individual basis.

\section{A.3. Other Descriptive Statistics}

Figure A1 shows the Kaplan-Meier survival function estimates of the normalized duration. We observe that about two thirds of calls are made before $50 \%$ of their callable life span has elapsed for callable non-convertible bonds.

Figure A1 illustrates that $11.7 \%$ of calls are made right after the absolute call protection period ends whereas $19.7 \%$ of calls are left unexercised until maturity for the callable non-convertible bonds.

To see whether the normalized duration differs systematically across callable bonds of different life spans, we draw scatter plots of the normalized duration against the callable life span. Figure A2 shows this. We also include simple linear regression lines with correlation coefficients.

The scatter plot shows that a callable bond with a longer life span is called earlier in terms of percentage of life. We naturally expect the call hazard rate to be higher for a callable bond with a longer life span than for a similar bond with a shorter life span at each percentage point in callable life. 


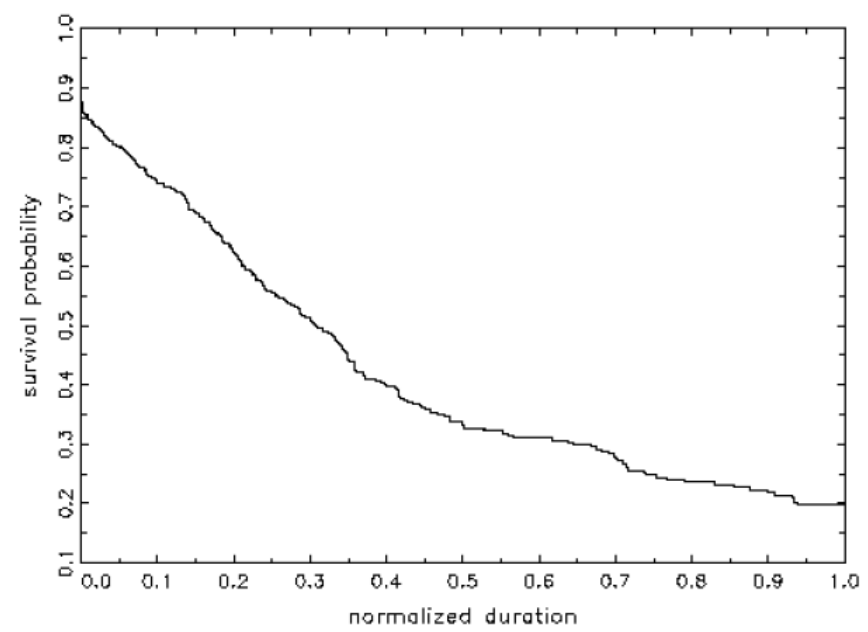

Figure A1: Survival function estimate for normalized duration.

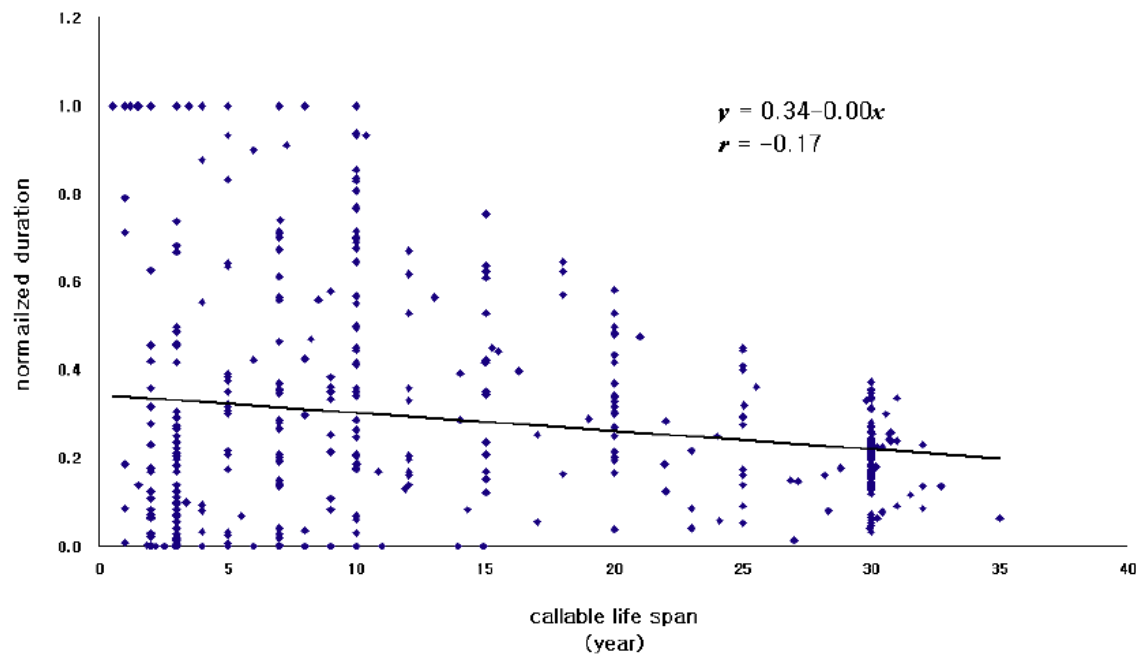

Figure A2: Scatter plot showing normalized call time vs. callable life span.

\section{A.4. Other Estimation Results}

Tables A1 show the call hazard function estimates for each sub-sample classified by the presence/absence of conditional call protection periods.

Table A1: Call Hazard Function Estimates: Non-Convertible Bonds with Conditional Call Clause

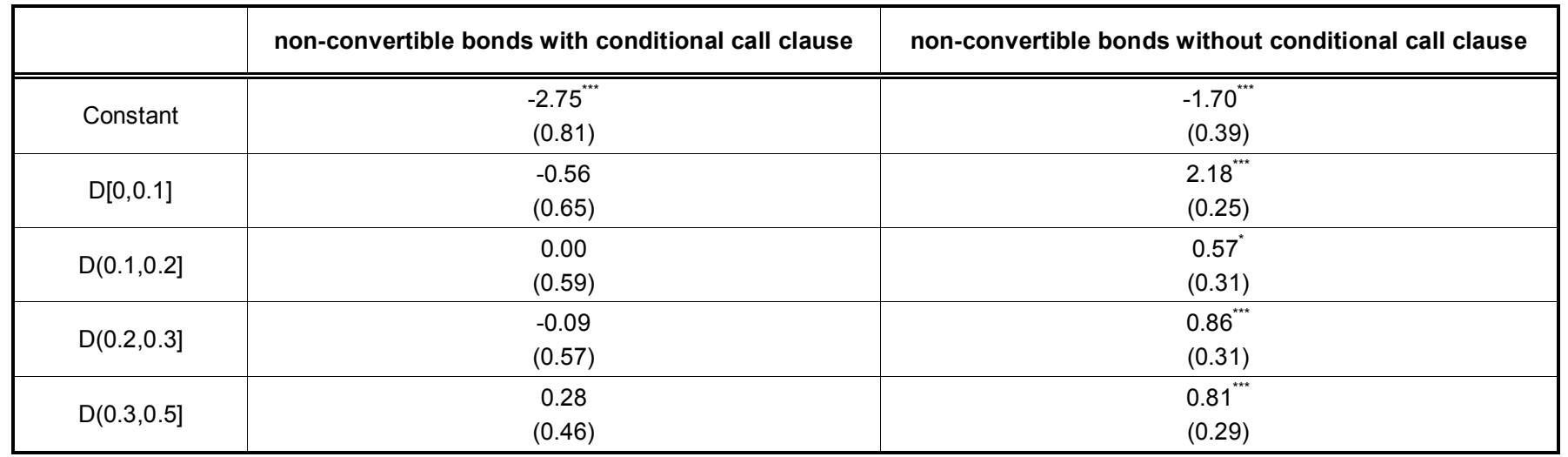




\begin{tabular}{|c|c|c|}
\hline FASS & $\begin{array}{l}-0.03 \\
(0.47)\end{array}$ & $\begin{array}{c}0.40 \\
(0.41)\end{array}$ \\
\hline DEBT & $\begin{array}{l}-2.08^{* * *} \\
(0.60)\end{array}$ & $\begin{array}{l}-2.21^{* * *} \\
(0.55)\end{array}$ \\
\hline PRO & $\begin{array}{l}4.92^{\text {*** }} \\
(1.64)\end{array}$ & $\begin{array}{l}5.18^{* \star *} \\
(1.68)\end{array}$ \\
\hline$D_{\text {FREE }}$ & $\begin{array}{c}0.48 \\
(0.37) \\
\end{array}$ & \\
\hline DINTxIn(Amount) & $\begin{array}{l}0.08^{* * *} \\
(0.02)\end{array}$ & $\begin{array}{l}0.05^{* * *} \\
(0.01)\end{array}$ \\
\hline Callable life span & $\begin{array}{l}0.52^{* * *} \\
(0.15)\end{array}$ & $\begin{array}{c}-0.01 \\
(0.11)\end{array}$ \\
\hline
\end{tabular}

\section{REFERENCES}

Allen, D. S., R. E. Lamy, and G. R. Thompson. 1987. "Agency Costs and Alternative Call Provisions: An Empirical Investigation." Financial Management (16): 37-44. https://doi.org/10.2307/3666107

Barnea, A., R. A. Haugen, and L. W. Senbet. 1980. "A Rationale for Debt Maturity Structure and Call Provisions in the Agency Theoretic Framework." Journal of Finance (35): 1223-34. https://doi.org/10.1111/j.1540-6261.1980.tb02205.x

Boyce, W. M., and A. J. Kalotay. 1979. "Tax Differentials and Callable Bonds." Journal of Finance (34): 825-38. https://doi.org/10.1111/j.1540-6261.1979.tb03438.x

Cornett, M. M., and N. G. Travlos. 1989. "Information Effects Associated with Debt-for-Equity and Equity-for-Debt Exchange Offers." Journal of Finance (44): 451-68. https://doi.org/10.1111/j.1540-6261.1989.tb05065.x

Crabbe, L. E., and J. Helwege. 1994. "Alternative Tests of Agency Theories of Callable Corporate Bonds." Financial management (23): 3-20. https://doi.org/10.2307/3666079

Fischer, E. O., R. Heinkel, and J. Zechner. 1989. "Dynamic Recapitalization Policies and the Role of Call Premia and Issue Discounts." Journal of Financial and Quantitative Analysis (24): 427-46. https://doi.org/10.2307/2330977

Green, R. C. 1984. "Investment Incentives, Debt and Warrants." Journal of Financial Economics (13): 115-36. https://doi.org/10.1016/0304-405X(84)90034-5

King, T. D. and D. Mauer. 2000. "Corporate Call Policy for Nonconvertible Bonds." Journal of Business (73): 403-44. https://doi.org/10.1086/209648

Kish, R. J., and Livingston, M. 1992. "Determinants of the Call Option on Corporate Bonds." Journal of Banking and Finance (16): 687-703. https://doi.org/10.1016/0378-4266(92)90002-H

Myers, S. C., and N. S. Majluf. 1984. "Corporate Financing and Investment Decisions When Firms Have Information that
Investors Do Not Have." Journal of Financial Economics (13): 187-221. https://doi.org/10.1016/0304-405X(84)90023-0

Narayanan, M. P., and S. Lim. 1989. "On the Call Provision in Corporate Zero-Coupon Bonds." Journal of Financial and Quantitative Analysis (24): 91-103.

https://doi.org/10.2307/2330750

Pye, G.. 1966. The Value of the Call Option on a Bond. Journal of Political Economy (74): 200-5. https://doi.org/10.1086/259137

Robbins, E. H., and J. D. Schatzberg. 1986. "Callable Bonds: A RiskReducing Signaling Mechanism." Journal of Finance (41): 935-949. https://doi.org/10.1111/j.1540-6261.1986.tb04558.x

Sarkar, S. 2001. "Probability of Call and Likelihood of the Call Feature in a Corporate Bond." Journal of Banking and Finance (25): 505-33. https://doi.org/10.1016/S0378-4266(00)00085-6

Smith, C. M., and J. B. Warner. 1979. "On Financial Contracting: An Analysis of Bond Covenants." Journal of Financial Economics (7): 117-61. https://doi.org/10.1016/0304-405X(79)90011-4

Stein, J. C. 1992. "Convertible Bonds as Backdoor Equity Financing." Journal of Financial Economics (32): 3-21. https://doi.org/10.1016/0304-405X(92)90022-P

Thatcher, J. S. 1985. "The Choice of Call Provision Terms: Evidence of the Existence of Agency Costs of Debt." Journal of Finance (40): 549-61. https://doi.org/10.1111/j.1540-6261.1985.tb04972.x

Titman, S., and R. Wessels. 1988. "The Determinants of Capital Structure Choice." Journal of Finance (43): 1-19. https://doi.org/10.1111/j.1540-6261.1988.tb02585.x

$\mathrm{Vu}$, J. D. 1986. "An Empirical Investigation of Calls of NonConvertible Bonds." Journal of Financial Economics (16): 235-65. https://doi.org/10.1016/0304-405X(86)90062-0

DOI: https://doi.org/10.6000/1929-7092.2018.07.28

(C) 2018 Wee et al.; Licensee Lifescience Global.

This is an open access article licensed under the terms of the Creative Commons Attribution Non-Commercial License (http://creativecommons.org/licenses/by-nc/3.0/) which permits unrestricted, non-commercial use, distribution and reproduction in any medium, provided the work is properly cited. 